\title{
Dual energy CT findings in gout with rapid kilovoltage-switching source with gemstone scintillator detector
}

\author{
Elin Svensson ${ }^{1}$, Ylva Aurell', Lennart T. H. Jacobsson², Anton Landgren², Valgerdur Sigurdardottir ${ }^{2,3}$ and \\ Mats Dehlin ${ }^{2^{*}}$
}

\begin{abstract}
Background: A definite diagnosis of gout requires demonstration of monosodium urate crystals in synovial fluid or in tophi, which in clinical practice today seldom is done. Dual energy CT (DECT) has repeatedly been shown to be able to detect monosodium urate crystals in tissues, hence being an alternative method to synovial fluid microscopy. The vast majority of these studies were performed with CT scanners with two X-ray tubes. In the present study we aim to investigate if and at what locations DECT with rapid kilovoltage-switching source with gemstone scintillator detector (GSI) can identify MSU crystals in patients with clinically diagnosed gout. We also performed a reliability study between two independent readings.
\end{abstract}

Methods: Patients with new or established gout who had been examined with DECT GSI scanning of the feet at Sahlgrenska University Hospital, Mölndal between 2015 and 2018 were identified. Their medical records were sought for gout disease characteristics using a structured protocol. Urate deposits in MTP1, MTP 2-5, ankle/midfoot joints and tendons were scored semiquantatively in both feet and presence of artifacts in nail and skin as well as beam hardening and noise were recorded. Two radiologists performed two combined readings and scoring of the images, thus consensus was reached over the scoring at each occasion (Espeland et al., BMC Med Imaging. 2013;13: 4). The two readings were compared with kappa statistics.

Results: DECT GSI could identify urate deposits in the feet of all 55 participants with gout. Deposits were identified in the MTP-joints of all subjects but were also present in ankle/midfoot joints and tendons in 96 and 75\% respectively. Deposition of urate was predicted by longer disease duration (Spearman's Rho 0.64, $p<.0001$ ) and presence of tophi ( $p=0.0005)$. Artifacts were common and mostly found in the nails $(73 \%)$, a minority displayed skin artifacts (31\%) while beam hardening and noise was rare. The agreement between the two readings was good $(\mathrm{K}=0.66,95 \% \mathrm{Cl}=0.61-0.71)$.

Conclusion: The validity of DECT GSI in gout is supported by the identification of urate in all patients with clinical gout and the good correlations with clinical characteristics. The occurrence of artifacts was relatively low with expected locations.

Keywords: Gout, Dual energy CT, Monosodium urate crystals, Foot, Diagnostic imaging

\footnotetext{
* Correspondence: mats.dehlin@vgregion.se

${ }^{2}$ Department of Rheumatology and Inflammation Research, Sahlgrenska

Academy, Gothenburg, Sweden

Full list of author information is available at the end of the article
}

(c) The Author(s). 2020 Open Access This article is distributed under the terms of the Creative Commons Attribution 4.0 International License (http://creativecommons.org/licenses/by/4.0/), which permits unrestricted use, distribution, and reproduction in any medium, provided you give appropriate credit to the original author(s) and the source, provide a link to the Creative Commons license, and indicate if changes were made. The Creative Commons Public Domain Dedication waiver (http://creativecommons.org/publicdomain/zero/1.0/) applies to the data made available in this article, unless otherwise stated. 


\section{Introduction}

Gout is world wide the most common inflammatory arthritis and is caused by the deposition of monosodium urate (MSU) crystals in joints, tendons and various tissues which may cause an inflammatory response, clinically recognized as an acute episode of gout. The gold standard for diagnosis is the demonstration of MSU crystals in the synovial fluid of an affected joint or in larger deposits of urate, so called tophi. However, in clinical practice joint aspiration is seldom performed [1] and the majority of patients do not have visible tophi. This is reflected in the ACR/EULAR classification criteria for gout from 2015 where imaging evidence of urate deposition by ultrasound or dual energy CT (DECT) is included as an important item [2].

DECT has been shown capable of detecting MSU crystals with high precision in many studies [3-6].

However, the vast majority of these studies were performed on CT scanners with two X-ray tubes (dual source) while the performance of other technical CT solutions are much less studied. As of today, there are five different types of DECT scanners available: dual source DECT, twin-beam single-source CT with gold filter, rapid kilovoltage-switching source with gemstone scintillator detector (GSI), dual-layer multidetector DECT, and dual-scan single source [7, 8].

Of course, detection of urate deposits with DECT does not come without artifacts, which potentially could lead to misclassification. Not all material color coded as urate on DECT images corresponds to likely or actual deposits of urate. Reported sites of such artifacts include the skin, nose, calluses and nail bed [7]. Other recorded artifacts that might result in false coloring at the DECT image are motion artifacts, noise and beam hardening artifacts [7]. Noise is a randomly unwanted change in pixel values which in the DECT context means that a single pixel being colored might be considered false. The signal to noise ratio $(\mathrm{S} / \mathrm{N})$ varies significantly between different technical solutions throughout the imaging process and is always of concern while assessing radiological image quality. Beam hardening is an artifact due to the phenomenon that low energy $\mathrm{x}$-ray photons do not always pass the whole way through the patient and thus the $x$-ray beam becomes "hardened" i.e. more energetic during its passage, which in particular is seen in relation to metallic implants and sometimes in relation to bone cortex.

There are great differences between the different technical DECT solutions. In the present study, all examinations were performed with a single source system (DECT GSI) in which the tube switches between $80 \mathrm{kVp}$ and $140 \mathrm{kVp}$ within less than $0.03 \mu \mathrm{s}$. The special scintillator detector $\left(G\right.$ mstone ${ }^{\circ}$ ) can read the data separately with very low afterglow, which gives a very high spatiotemporal resolution. The dual source technique requires much longer time to obtain the two data sets (about70 ms) and they are initially reconstructed separately by filtered back projection and the material decomposition is performed afterwards. With the DECT GSI technique the time between the two energy projection levels is so short that it enables another algorithm for material decomposition, which is done directly and using raw data. Theoretically this technical solution will give not only a more accurate material decomposition information but should be more robust for artifacts such as beam-hardening and motion artifacts [8].

In the present study we wanted to investigate if DECT GSI could detect MSU crystals in patients with clinically diagnosed gout and to correlate the findings against clinical characteristics of gout. We also performed a reliability study between the two combined readings of DECT GSI images.

\section{Methods}

Patients with new or established gout who all fulfilled the ACR/EULAR classification criteria for gout [2] and had been examined with DECT GSI scanning of the feet at Sahlgrenska University Hospital, Mölndal between 2015 and 2018 as part of clinical diagnostics or disease monitoring of gout were identified. They all had at least one ICD-10 diagnosis of gout (M10) in their medical records. Their medical records were examined according to a structured protocol for gout disease characteristics including information on onset of disease, presence of tophi, comorbidities (ischemic heart disease (IHD), hypertension (HT), dyslipidemia), treatment with loop or thiazide diuretics or urate lowering therapy (ULT), body mass index (BMI), serum urate level at time of DECT, and renal function described as eGFR calculated by the CKD-EPI formula [9].

All radiographic examinations were performed using a single source dual-energy CT system (Discovery CT750HD, GE Healthcare, Milwaukee, WI, USA) with 64 detectors and a scan field of view of $32 \mathrm{~cm}$. The tube voltage of the system is switched extremely rapidly, in less than $0.03 \mu \mathrm{s}$, between the two different energy levels i.e. $80 \mathrm{kVp}$ and 140 $\mathrm{kVp}$, both at $550 \mathrm{~mA}$. The slice thickness was $0.625 \mathrm{~mm}$, pitch 0.516 and rotation time $0.8 \mathrm{~s}$.

All patients were scanned with the feet resting at the gantry-table, holding the knee in a flexed position and the scanning volume included the whole foot and ankle bilaterally.

Urate deposits in MTP1, MTP 2-5, ankle/midfoot joints and tendons were scored semiquantatively in both feet in the following manner: $0=$ no deposit, $1=$ dots, $2=$ single deposit and $3=$ more than 1 deposit, thus a maximum score of 12 per foot [10]. Presence of artifacts in nail and skin as well as beam hardening and noise 
were also identified and recorded. All images were examined by one experienced radiologist and one junior radiologist who read and scored all images together. If disagreement, images were read together until consensus was reached [11]. This procedure was performed twice.

DECT GSI findings for the total score of urate depositions in the joints and tendons in both feet were analyzed according to demographics (age and gender), features of gout (disease duration, presence of tophi, presence of joint erosions, urate levels at time of DECT defined as low $\leq 405 \mu \mathrm{mol} / \mathrm{L}$ and high $>405 \mu \mathrm{mol} / \mathrm{L}$ ), diuretic and ULT use, BMI defined as high $\geq 30$ and renal function by eGFR in the following categories: $>90$, $60-90$ and $<60 \mathrm{ml} / \mathrm{min}$ per $1.73 \mathrm{~m}^{2}$.

Baseline characteristics are expressed as absolute counts and proportions for categorical variables, and as means \pm standard deviations for continuous variables. The Wilcoxon Mann-Whitney test and Chi-2 tests were used when appropriate to study associations between subgroups and study variables (total urate deposits, age, gender, presence of tophus, erosive disease, disease duration, urate level at DECT, loop or thiazide diuretic use, BMI, renal function). Spearman correlation coefficients were used to assess correlations between total urate deposits on DECT GSI and continuous factors (disease duration, serum urate). BMI was defined as high if $\geq 30$ $\mathrm{kg} / \mathrm{m}^{2}$, which corresponds to the internationally accepted definition of obesity. Correlation coefficients above the threshold of 0.30 were considered relevant and nominal $p$-values $<0.05$ were considered statistically significant. Agreement between the two readings of DECT images were evaluated by kappa statistics.

\section{Results}

We identified a total of 55 patients with a clinical diagnosis of new or established gout who had been examined with DECT GSI scanning of both feet, 43 men and 12 women, with a mean age of $60(\mathrm{SD}=16)$ years for the men and $53(\mathrm{SD}=14)$ years for the women (Table 1). All patients fulfilled the ACR/EULAR classification criteria for gout [2]. Mean disease duration was 7 years $(S D=7)$, presence of tophi was more common among the women while erosive disease was more common in the men (Table 1). Comorbidities such as HT, IHD and dyslipidemia were more common in men while obesity was much more common among the women, $75 \%$ compared to $35 \%$ of the men (Table 1). A minority of the patients, $40 \%$, were on ULT (allopurinol) at the time of DECT GSI examination with a mean dose of $210 \mathrm{mg}$ daily. The total population had a mean serum urate level above the recommended target level, $360 \mu \mathrm{mol} / \mathrm{L}$, irrespective of whether they were on ULT (40\%) or not. (Table 1). A third of the patients had eGFR below $60 \mathrm{~mL} / \mathrm{min} / 1.73 \mathrm{~m}^{2}$ (Table 1 ).

All patients displayed urate deposits on DECT GSI of the feet, most commonly seen in the MTP-joints but also often present in ankle/midfoot joints and tendons (Figs. 1 and 2, Table 2). Women tended to have more deposits, especially in the tendons, although these differences were not significant (Table 2).

Table 1 Characteristics of study population overall and by gender

\begin{tabular}{|c|c|c|c|}
\hline & Total, $n=55$ & Men, $n=43$ & Women, $n=12$ \\
\hline Age, mean years (SD) & $58(15)$ & $60(16)$ & $53(14)$ \\
\hline Disease duration, mean years (SD) & $7(7)$ & $6(7)$ & $9(8)$ \\
\hline Tophus, n (\%) & $7(13)$ & $4(9)$ & $3(25)$ \\
\hline Erosive disease, n (\%) & $36(65)$ & $29(67)$ & $7(58)$ \\
\hline IHD, n (\%) & $15(29) n=51$ & $12(29), n=42$ & $3(33), n=9$ \\
\hline HT, n (\%) & $29(54) n=54$ & $23(53), n=43$ & $6(55), n=11$ \\
\hline Dyslipidemia, n (\%) & $15(29) n=51$ & $14(33), n=43$ & $1(11), n=9$ \\
\hline Diuretic use, n (\%) & $16(29)$ & $12(28)$ & $4(33)$ \\
\hline ULT at DECT, n (\%) & $22(40)$ & $16(37)$ & $6(50)$ \\
\hline BMI high $\geq 30, n(\%)$ & $20(48) n=42$ & $12(38), n=32$ & $8(75), n=10$ \\
\hline Urate at $\mathrm{DECT}, \mu \mathrm{mol} / \mathrm{L}$, mean $(\mathrm{SD})$ & 457 (134) & $465(133)$ & $424(137)$ \\
\hline Urate at DECT, $\mu \mathrm{mol} / \mathrm{L}$, mean (SD) with ULT, $n=22$ & $405(114)$ & $401(93), n=16$ & $418(168), n=6$ \\
\hline Urate at DECT, $\mu \mathrm{mol} / \mathrm{L}$, mean (SD) without ULT, $n=33$ & $491(137)$ & $504(140), n=27$ & $429(113), n=6$ \\
\hline eGFR > 90, n (\%) & $16(29)$ & $12(28)$ & $4(33)$ \\
\hline eGFR 60-90, n (\%) & $20(36)$ & $15(35)$ & $5(42)$ \\
\hline eGFR < 60, n (\%) & $19(35)$ & $16(37)$ & $3(25)$ \\
\hline
\end{tabular}

Abbrevaition: $\mathrm{SD}=$ standard deviation, $\mathrm{IHD}=$ ischemic heart disease, $\mathrm{HT}=$ hypertension, $\mathrm{ULT}=$ urate lowering treatment, $\mathrm{BMI}=$ body mass index 


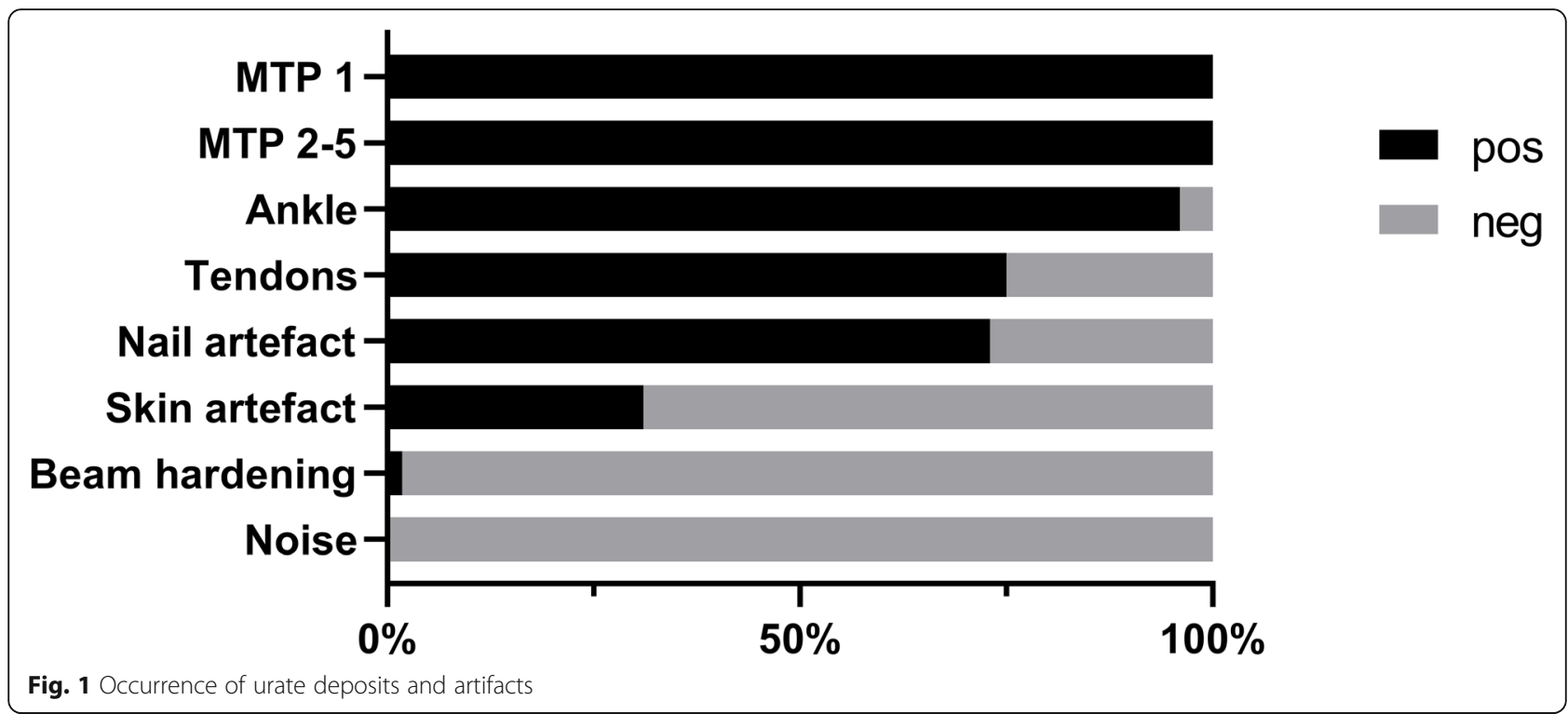

The majority of patients (73\%) displayed nail artifacts while skin artifacts only were seen in 31\% (Figs. 1 and 2, Table 2). Beam hardening was only found in one patient and noise was not seen at all (Fig. 1, Table 2).

Agreement between the two combined readings of DECT images were good (Kappa $=0.66,95 \% \mathrm{CI}=$
0.61-0.71). The total urate deposit score was significantly higher in the presence of tophus $(p=0.0005)$ and correlated strongly to disease duration (Spearman Rho $0.64, p<.0001$ ) while no association or correlation was seen to age, gender, erosive disease, urate levels, BMI, diuretic use, ULT use or renal function (Table 3).

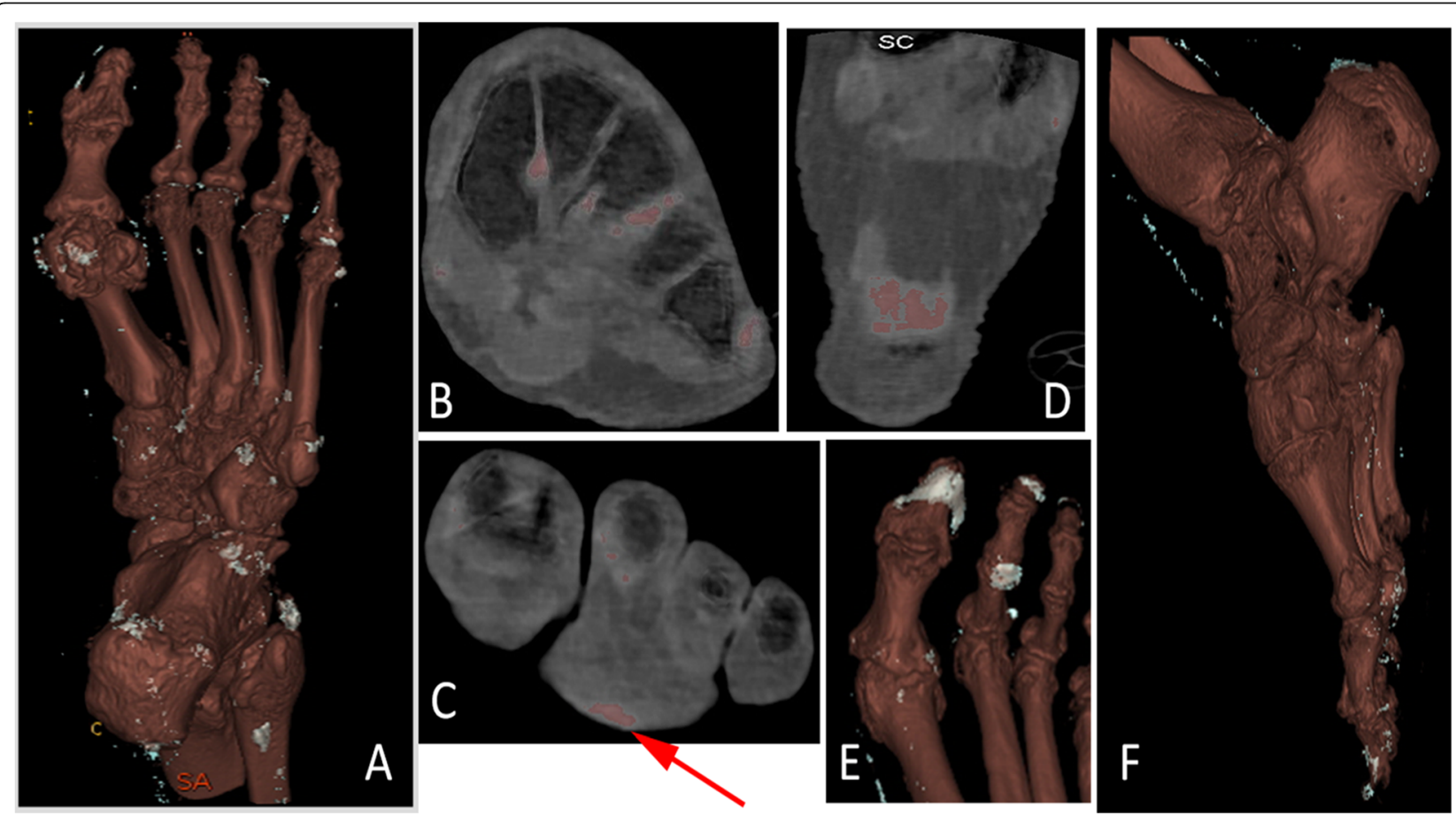

Fig. 2 a-f figure depicting typical findings of urate deposition and typical artifacts. 3D reconstruction, scoring of the foot of a patient with a total score of $24 \mathbf{a}$ and the axial scan of the same right midfoot $\mathbf{b}$. Artifacts from the skin (red arrow) $\mathbf{c}$ and note the high amount of colour coded urate in the Achilles tendon insertion $\mathbf{d}$ and nail bed artifact $\mathbf{e}$. Example of scoring, score 3 for tendons in the foot $\mathbf{f}$ 
Table 2 Urate deposits in joints and tendons and presence of artifacts in the total population and stratified by gender

\begin{tabular}{|c|c|c|c|c|}
\hline & Total, $n=55$ & Men, $n=43$ & Women, $\mathrm{n}=12$ & $p$-value* \\
\hline \multicolumn{5}{|l|}{ All joints and tendons, } \\
\hline score (SD) & $14.0(5.5)$ & $13.5(5.4)$ & $16.1(5.4)$ & 0.09 \\
\hline \multicolumn{5}{|l|}{ MTP1, } \\
\hline n positive (\%) & $55(100)$ & $43(100)$ & $12(100)$ & \\
\hline score (SD) & $4.0(1.5)$ & $3.9(1.5)$ & $4.2(1.7)$ & 0.5 \\
\hline \multicolumn{5}{|l|}{ MTP 2-5, } \\
\hline n positive (\%) & $55(100)$ & $43(100)$ & $12(100)$ & \\
\hline score (SD) & $3.9(1.7)$ & $3.8(1.8)$ & $4.2(1.7)$ & 0.6 \\
\hline \multicolumn{5}{|l|}{ Ankle/midfoot, } \\
\hline n positive (\%) & $53(96)$ & $42(98)$ & $11(92)$ & \\
\hline score (SD) & $3.6(1.8)$ & $3.5(1.8)$ & $3.8(2.0)$ & 0.6 \\
\hline \multicolumn{5}{|l|}{ Tendons, } \\
\hline n positive (\%) & $41(75)$ & $31(72)$ & $10(83)$ & \\
\hline score (SD) & $2.5(2.3)$ & $2.2(2.2)$ & $3.5(2.5)$ & 0.1 \\
\hline \multicolumn{5}{|l|}{ Nailartifact, } \\
\hline n positive (\%) & $40(73)$ & $32(74)$ & $8(67)$ & \\
\hline \multicolumn{5}{|l|}{ Skinartifact, } \\
\hline n positive (\%) & $17(31)$ & $12(28)$ & $5(42)$ & \\
\hline \multicolumn{5}{|l|}{ Beam hardening, } \\
\hline n positive (\%) & $1(1.8)$ & $1(2)$ & 0 & \\
\hline Noise, n positive (\%) & 0 & 0 & 0 & \\
\hline
\end{tabular}

${ }^{*} p$-value comparing men and women

\section{Discussion}

In the present study we show that DECT GSI identified urate deposits in the feet of all 55 participants with gout, most commonly seen in the MTP-joints but also often in ankle/midfoot joints and tendons. Furthermore, more depositions were identified in patients with one or more tophi and longer disease duration of gout. Artifacts were mostly found in the nails, a minority displayed skin artifacts while beam hardening and noise was almost not seen at all. The agreement between the two repeated consensus readings was good.

The DECT GSI method has been methodically tested and shown to be able to detect MSU deposits by Li et al. 2014 [12]. Kiefer et al. compared single source DECT with conventional $\mathrm{CT}$ and digital radiography and showed that it had the best diagnostic properties of the three for gout diagnosis [13]. However, the vast majority of DECT studies on urate deposition have been performed with dual source machines. For example, Dalbeth et al. [14] showed that the presence of tophi and disease duration were associated with both presence and amount of MSU deposits seen with dual source DECT. Furthermore, they also demonstrated that higher urate levels, lower allopurinol dose, higher number of attacks and attack within three months were associated with higher amounts of MSU deposits. In our study we found no correlation to use of allopurinol but that may be explained by suboptimal dosing of ULT in the present setting, as we have demonstrated before [15].

Artifacts are common in DECT for MSU deposition identification but they are usually readily recognizable. In our study we found quite low numbers of skin artifacts and noise compared to dual source examination [16]. Furthermore, artifacts in the form of beam hardening was only seen in one individual in the present study and motion artifacts were not seen at all. The latter is probably explained by the rapid reconstruction algorithms made possible by the ultrafast scintillator detector of the DECT GSI equipment [16, 17].

There are several strengths to the present study. First, all images were evaluated by two DECT radiologists in two repeated combined readings. Second, the agreement between readings was good. Third, we correlated the DECT findings with extensive data retrieved from medical records.

There are also limitations to our study. First, the study was cross-sectional and therefore not able to identify changes in deposition over time in relation to ULT. Second, in the medical records we did not have reliable data on gout attack characteristics, such as severity and 
Table 3 Associations between total urate deposit score and demographics, gout characteristics, diuretic and ULT use, BMI and renal function

\begin{tabular}{|c|c|c|}
\hline Parameter & $\mathrm{n}$ & $\begin{array}{l}\text { Total urate deposit score correlation } \\
\text { coefficient }\end{array}$ \\
\hline Age & 55 & -0.23 \\
\hline$p$-value & & 0.09 \\
\hline Disease duration, years & 55 & 0.64 \\
\hline$p$-value & & $<.0001$ \\
\hline Urate at DECT & 55 & -0.12 \\
\hline \multirow[t]{2}{*}{$p$-value } & & 0.36 \\
\hline & $\mathrm{n}$ & Total urate deposit score, mean \\
\hline Age categories & 55 & \\
\hline$<65$ years & 24 & $13.6(5.8)$ \\
\hline$>65$ years & 31 & $14.4(5.3)$ \\
\hline$p$-value & & 0.5 \\
\hline Gender & 55 & \\
\hline Men & 43 & $13.5(5.4)$ \\
\hline Women & 12 & $16.1(5.4)$ \\
\hline$p$-value & & 0.09 \\
\hline Tophus & 55 & \\
\hline Yes & 7 & $21.1(3.2)$ \\
\hline No & 48 & $13.0(5.0)$ \\
\hline$p$-value & & 0.0005 \\
\hline Erosive disease & 55 & \\
\hline Yes & 36 & $14.3(5.6)$ \\
\hline No & 19 & $13.6(5.6)$ \\
\hline$p$-value & & 0.7 \\
\hline Presence of nail artifacts & 55 & \\
\hline Yes & 40 & $14.3(4.0)$ \\
\hline No & 15 & $13.5(4.5)$ \\
\hline$p$-value & & 0.7 \\
\hline Presence of skin artifacts & 55 & \\
\hline Yes & 17 & $15.6(5.3)$ \\
\hline No & 38 & $13.3(5.5)$ \\
\hline$p$-value & & 0.2 \\
\hline Disease duration, years & 55 & \\
\hline Short $\leq 7$ & 35 & $11.9(4.8)$ \\
\hline Long $>7$ & 20 & $17.8(4.6)$ \\
\hline$p$-value & & 0.0002 \\
\hline Urate at DECT & 55 & \\
\hline$\leq 405 \mu \mathrm{mol} / \mathrm{L}$ & 19 & $15.1(5.5)$ \\
\hline$>405 \mu \mathrm{mol} / \mathrm{L}$ & 36 & $13.5(5.5)$ \\
\hline$p$-value & & 0.18 \\
\hline
\end{tabular}

Table 3 Associations between total urate deposit score and demographics, gout characteristics, diuretic and ULT use, BMI and renal function (Continued)

\begin{tabular}{lll}
\hline Parameter & $n$ & $\begin{array}{l}\text { Total urate deposit score correlation } \\
\text { coefficient }\end{array}$ \\
\hline ULT use at DECT & 55 & \\
$\quad$ Yes & 22 & $14.9(5.4)$ \\
No & 33 & $13.5(5.5)$ \\
$p$-value & & 0.2 \\
Diuretic use & 55 & \\
Yes & 16 & $13.9(5.1)$ \\
No & 39 & $14.1(5.7)$ \\
$p$-value & & 0.8 \\
BMI & 42 & \\
$<30$ & 22 & $13.6(6.1)$ \\
$\geq 30$ & 20 & $13.4(5.4)$ \\
$p$-value & & 0.9 \\
Renal function by eGFR & 55 & \\
$\geq 90$ & 16 & $13.8(5.2)$ \\
$60-90$ & 20 & $12.8(5.3)$ \\
$<60$ & 19 & $15.5(5.8)$ \\
$p$-value & & 0.4 \\
\hline
\end{tabular}

frequency of attacks. Third, almost all subjects were patients at a rheumatology clinic and thus possibly including patients with more severe gout than what is on average seen in primary care. Fourth, the lack of a control group without gout limited the estimation of artifacts. Fifth, examination of the study subjects with other DECT techniques would have rendered important information but was not possible due to the retrospective design of the study. We are however planning a prospective study for such comparisons. Finally, validity was not tested against microscopy of tissue samples collected at sites where DECT indicated deposition of urate. However, such studies have been performed previously, although only on dual source CT scanners, and in all cases shown both high sensitivity and specificity $[3,18]$.

DECT is an important tool to help clinicians when diagnosing gout but availability is limited due to costs and lack of radiologists. It is therefore important to gain knowledge on the performance of the different available DECT techniques to eliminate that as an obstacle in implementing the procedure. Thus, there is a need for comparative studies between the different DECT techniques and their ability to detect MSU deposits.

To conclude, in the present study we show that DECT GSI performs well in detecting MSU deposits with a low frequency of artifacts in gout patients and amount of deposits correlate with disease duration and presence of tophus. 


\section{Abbreviations}

BMI: body mass index; DECT: dual energy CT; GSI: gemstone scintillator detector; HT: hypertension; IHD: ischemic heart disease; MSU: monosodium urate; ULT: urate lowering therapy

\section{Acknowledgements}

Anders Emgård, radiographer.

\section{Authors' contributions}

All authors were involved in the conception and design of the study. MD, $L$, AL and VS contributed to the acquisition of the data. YA and ES read and scored the images. All authors contributed to analysis and interpretation of the data and take responsibility for the integrity of the data and the accuracy of the analyses. All authors participated in the drafting of the manuscript or revised it critically for intellectual content. All authors approved the final version to be published.

\section{Funding}

This study was supported by grants from The University of Gothenburg and The Swedish Rheumatism Association. They had no role in data collection, analysis of data or writing the manuscript. Open access funding provided by University of Gothenburg.

\section{Availability of data and materials}

The datasets used and/or images analyzed during the current study are available from the corresponding author on reasonable request.

\section{Ethics approval and consent to participate}

Ethical approval for the study was granted by the Ethical Review Board of Gothenburg, Sweden (489-17). Informed consent from the patients was not needed as the study only involved retrospective review of medical records and scoring of radiographic images and no actual handling of patients.

\section{Consent for publication}

Not applicable.

\section{Competing interests}

The authors declare that they have no competing interests.

\section{Author details}

'Department of Radiology at Institute of Clinical Sciences, Sahlgrenska Academy, Gothenburg, Sweden. ${ }^{2}$ Department of Rheumatology and Inflammation Research, Sahlgrenska Academy, Gothenburg, Sweden. ${ }^{3}$ Center of Clinical Research (CKF) Dalarna, Uppsala University, Uppsala, Sweden.

Received: 26 June 2019 Accepted: 30 October 2019

Published online: 17 January 2020

\section{References}

1. Dehlin M, Stasinopoulou K, Jacobsson L. Validity of gout diagnosis in Swedish primary and secondary care - a validation study. BMC Musculoskelet Disord. 2015;16:149.

2. Neogi T, Jansen TL, Dalbeth N, Fransen J, Schumacher HR, Berendsen D, Brown M, Choi H, Edwards NL, Janssens HJ, et al. 2015 gout classification criteria: an American College of Rheumatology/European league against rheumatism collaborative initiative. Arthritis Rheum. 2015;67(10):2557-68.

3. Bongartz T, Glazebrook KN, Kavros SJ, Murthy NS, Merry SP, Franz WB 3rd, Michet CJ, Veetil BM, Davis JM 3rd, Mason TG 2nd, et al. Dual-energy CT for the diagnosis of gout: an accuracy and diagnostic yield study. Ann Rheum Dis. 2015;74(6):1072-7.

4. Choi HK, Burns LC, Shojania K, Koenig N, Reid G, Abufayyah M, Law G, Kydd AS, Ouellette $H$, Nicolaou S. Dual energy $C T$ in gout: a prospective validation study. Ann Rheum Dis. 2012;71(9):1466-71.

5. Dalbeth N, House ME, Aati O, Tan P, Franklin C, Horne A, Gamble GD, Stamp LK, Doyle AJ, McQueen FM. Urate crystal deposition in asymptomatic hyperuricaemia and symptomatic gout: a dual energy CT study. Ann Rheum Dis. 2015;74(5):908-11.

6. Glazebrook KN, Guimaraes LS, Murthy NS, Black DF, Bongartz T, Manek NJ, Leng S, Fletcher JG, McCollough $\mathrm{CH}$. Identification of intraarticular and periarticular uric acid crystals with dual-energy $C T$ : initial evaluation. Radiology. 2011;261(2):516-24.
7. Coupal TM, Mallinson PI, Gershony SL, McLaughlin PD, Munk PL, Nicolaou S, Ouellette HA. Getting the most from your dual-energy scanner: recognizing, reducing, and eliminating artifacts. AJR Am J Roentgenol. 2016;206(1):119-28,

8. Forghani R, De Man B, Gupta R. Dual-energy computed tomography: physical principles, approaches to scanning, usage, and implementation: part 1. Neuroimaging Clin N Am. 2017;27(3):371-84.

9. Levey AS, Stevens LA, Schmid CH, Zhang YL, Castro AF 3rd, Feldman HI, Kusek JW, Eggers P, Van Lente F, Greene T, et al. A new equation to estimate glomerular filtration rate. Ann Intern Med. 2009;150(9):604-12.

10. Bayat S, Aati O, Rech J, Sapsford M, Cavallaro A, Lell M, Araujo E, Petsch C, Stamp LK, Schett G, et al. Development of a dual-energy computed tomography scoring system for measurement of Urate deposition in gout. Arthritis Care Res. 2016;68(6):769-75.

11. Espeland A, Vetti N, Krakenes J. Are two readers more reliable than one? A study of upper neck ligament scoring on magnetic resonance images. BMC Med Imaging. 2013;13:4.

12. Li X, Wang X, Yu Y, Liu B, Cai J, Xia L, Luo L, Wang W, Ding Q, Zhang C, et al. Detection of uric acid depositing in tophaceous gout using a new dual energy spectral CT technology. J Xray Sci Technol. 2014;22(4):541-9.

13. Kiefer T, Diekhoff T, Hermann S, Stroux A, Mews J, Blobel J, Hamm B, Hermann KG. Single source dual-energy computed tomography in the diagnosis of gout: diagnostic reliability in comparison to digital radiography and conventional computed tomography of the feet. Eur J Radiol. 2016; 85(10):1829-34.

14. Dalbeth N, Nicolaou S, Baumgartner S, Hu J, Fung M, Choi HK. Presence of monosodium urate crystal deposition by dual-energy $C T$ in patients with gout treated with allopurinol. Ann Rheum Dis. 2018;77(3):364-70.

15. Dehlin M, Ekstrom EH, Petzold M, Stromberg U, Telg G, Jacobsson LT. Factors associated with initiation and persistence of urate-lowering therapy. Arthritis Res Ther. 2017;19(1):6.

16. Mallinson PI, Coupal T, Reisinger C, Chou H, Munk PL, Nicolaou S, Ouellette $H$. Artifacts in dual-energy $C T$ gout protocol: a review of 50 suspected cases with an artifact identification guide. AJR Am J Roentgenol. 2014;203(1): W103-9.

17. Jeon JY, Lee SW, Jeong YM, Baek HJ. The effect of tube voltage combination on image artefact and radiation dose in dual-source dualenergy CT: comparison between conventional 80/140 kV and 80/150 kV plus tin filter for gout protocol. Eur Radiol. 2019;29(3):1248-57.

18. Glazebrook KN, Guimarães LS, Murthy NS, Black DF, Bongartz T, Manek NJ, Leng S, Fletcher JG, McCollough CH. Identification of intraarticular and periarticular uric acid crystals with dual-energy CT: initial evaluation. Radiology. 2011;261(2):516-24.

\section{Publisher's Note}

Springer Nature remains neutral with regard to jurisdictional claims in published maps and institutional affiliations.
Ready to submit your research? Choose BMC and benefit from:

- fast, convenient online submission

- thorough peer review by experienced researchers in your field

- rapid publication on acceptance

- support for research data, including large and complex data types

- gold Open Access which fosters wider collaboration and increased citations

- maximum visibility for your research: over $100 \mathrm{M}$ website views per year

At BMC, research is always in progress.

Learn more biomedcentral.com/submissions 